\title{
Design of Logistic Transporter Robot System
}

\author{
Lora Khaula Amifia ${ }^{1}$, Moch. Iskandar Riansyah ${ }^{2}$, Putu Duta Hasta P. ${ }^{3}$ \\ ${ }^{1,2,3}$ Electrical Engineering, Institut Teknologi Telkom Surabaya, Surabaya, Indonesia
}

\begin{tabular}{ll}
\hline ARTICLE INFO & ABSTRACT \\
\cline { 2 - 2 } $\begin{array}{l}\text { Article historys: } \\
\text { Received 20 May 2020, } \\
\text { Revised 30 June 2020, } \\
\text { Accepted 25 July 2020. }\end{array}$ & $\begin{array}{l}\text { The diversity of technology in the robotics world is currently developing a lot, } \\
\text { especially in logistics distribution. The distribution of logistics goods using } \\
\text { robotic power continues to develop towards high artificial intelligence, } \\
\text { ensuring warehouse delivery management and intelligence implementation } \\
\text { with challenging tasks. Autonomous robots are a community of intelligent } \\
\text { robotic systems that can be seen as prototypes. It is an intelligent management } \\
\text { and service system of the future that can reveal some important traits of the } \\
\text { Keywords: }\end{array}$ \\
$\begin{array}{l}\text { next generation of smart robot communities. In the smart logistics industry, } \\
\text { designing an efficient communication and management platform from }\end{array}$ \\
$\begin{array}{l}\text { logistics robots is one of the fundamental problems. This study aims to } \\
\text { implement smart robots in assisting distribution / logistical activities by } \\
\text { following humans in bringing goods to the intended area by following green } \\
\text { Rogistic Robot, } \\
\text { objects. }\end{array}$
\end{tabular}

This work is licensed under a Creative Commons Attribution-Share Alike 4.0

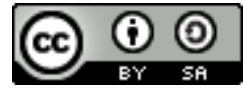

Corresponding Author:

Lora Khaula Amifia,

Institut Teknologi Telkom Surabaya, Surabaya, Indonesia.

Email: loraamifia@ittelkom-sby.ac.id

\section{INTRODUCTION}

The logistics sector is one of the fields that is developing and influencing national economic growth. It consists of people, processes (operational practices), and technology [1]. In the millennial era, intelligent devices based on information and communication technology are needed to make the system effective and efficient which leads to industry 4.0 [2]. In addition, many intelligent devices can help daily human activities, for example using artificial intelligence (AI), robotics, strength and energy.

The development of information and communication technology makes the community needs an effective and efficient device and has a "smart" value as implemented. Smart in this case is able to help humans significantly. One of contributions that can be easily implemented in the environment around us is the logistics devices developed in robotics, for example in warehousing [3]. The distribution of warehousing and shipping goods is the purpose of this research. Nowadays, people still use conventional energy to move one item to another place. In Lazada, Pos Indonesia, JNE, human labor becomes the main in the distribution of logistics goods so it requires a lot of resources and requires more time. Automatic Line follower based robot delivery machine has been implemented to assist the process of transporting goods and working semi-automatically. This is effectively done and this research develops it by adding the Obstacle Avoidance algorithm [4].

In other studies, new path planning methods for the mobile robots have been developed and implemented. Robot moves based on the shortest path from the starting point to the destination point, this path planner can choose the best direction of moving [5] [6]. Whereas in other cases, intelligent obstacle avoidance can find a target point with the shortest path length while avoiding some infinite loop traps from some obstacles in an unknown environment [7]. In addition, with continuous updates of onboard sensor information, this approach can produce mobile robot trajectories that are both static and dynamic.

This research will implement intelligent logistics robots effectively and efficiently to assist human work in the distribution of logistics goods using Human Following Robot and Obstacle Avoidance Algorithm. Thus, warehousing and shipping units have the ability to run the algorithm intelligently, correctly, safely and efficiently. 


\section{RESEARCH METHOD}

This research has a simple method that will be tested in the Institut Teknologi Telkom Surabaya environment before it is developed into industry; the weight of the item is not more than $10 \mathrm{~kg}$; and the contribution in this research is the effectiveness and efficiency of logistics goods transfer time.

\subsection{Design of Transporter}

The purpose of this research is to create an intelligent logistics robot that can move goods automatically, so there is no need for a manual to do this. However, the system designed in this experiment is that robots can follow people who will move logistics goods in warehouses from one location to another by using the method of recognition and tracking the motion of an object to be followed. In this case the robot follows the green object. In addition, the system designed has the ability to detect obstacles when the transporter follows the object to move goods by making the decision to stop the movement temporarily while the obstacle still exists. Block diagram of the system designed can be seen in the following Figure 1.

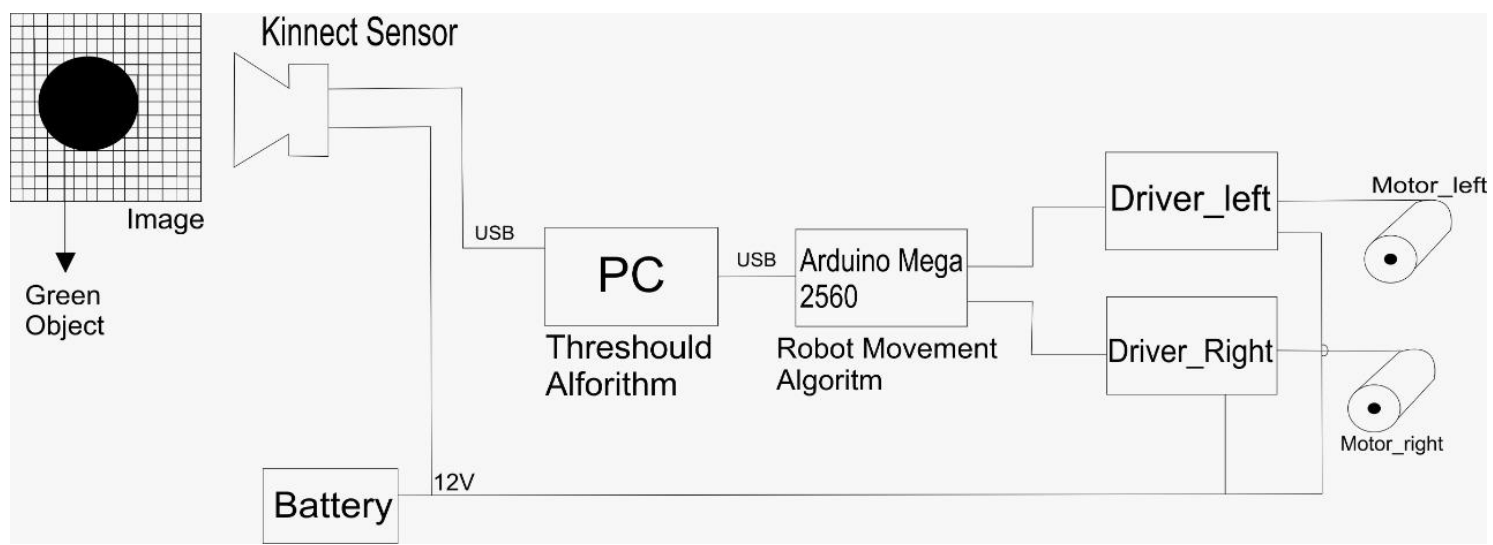

Fig. 1. Block System Diagram

The working principle of the system block diagram is as follows:

- The camera sensor captures the green object in front of it, then the data enters through the USB cable that enters the PC in which there is a threshold algorithm.

- Thresholding is one method of image segmentation with a process based on differences in image gray degree, the intensity value of the image is more than or equal to the threshold value will be changed to white (1) while the image intensity value less than the threshold value will be changed to black (0), so that the output of the thresholding results is in the form of a binary image.

- Arduino Mega that uses IC Microcontroller ATmega 2560 is a robot drive algorithm. This board has a relatively large number of I / O pins, 54 digital inputs / outputs, 15 of which can be used as PWM outputs, 16 analog inputs, and 4 UARTs. Arduino Mega 2560 equipped with $16 \mathrm{Mhz}$ crystals for relatively simple use, namely by connecting power from USB to PC or via DC jack using a 7-12 V DC adapter.

- Furthermore, the robot works optimally with the left and right drivers and the battery voltage source on the robot is $12 \mathrm{~V}$.

\subsection{Hardware of Smart Robot}

Intelligent logistic robot (transporter) in this study is called "Smart Robot (Srobot)" which acts as a human helper robot in the field of logistics or moving goods. The design of the Srobot system consists of a Kinect camera that serves to detect green images / objects. This camera is connected to the battery as a voltage supply and a PC that is used by researchers for algorithm implementation. While Arduino also functions as a robot amplifier algorithm. The robot hardware design is shown in Figure 2 and the hardware robot model / Srobot hardware design is obtained in real in Figure 3. The hardware that will be built consists of 4 parts, namely the image / image processing device and the following algorithm (follower), transporter drive device, data / command processing device, and obstacle detection device.

There are mathematical equations for the motor used by robots are as follows

$$
E_{a}=V_{t}-I_{a} R_{a}
$$




$$
\begin{gathered}
E_{a}=\frac{P \Phi Z_{n}}{x} \\
\frac{P \Phi Z_{n}}{x}=V_{t}-I_{a} R_{a} \\
n=\frac{V_{t}-I_{a} R_{a}}{\Phi}-x
\end{gathered}
$$

Image Processing and Following Algorithms

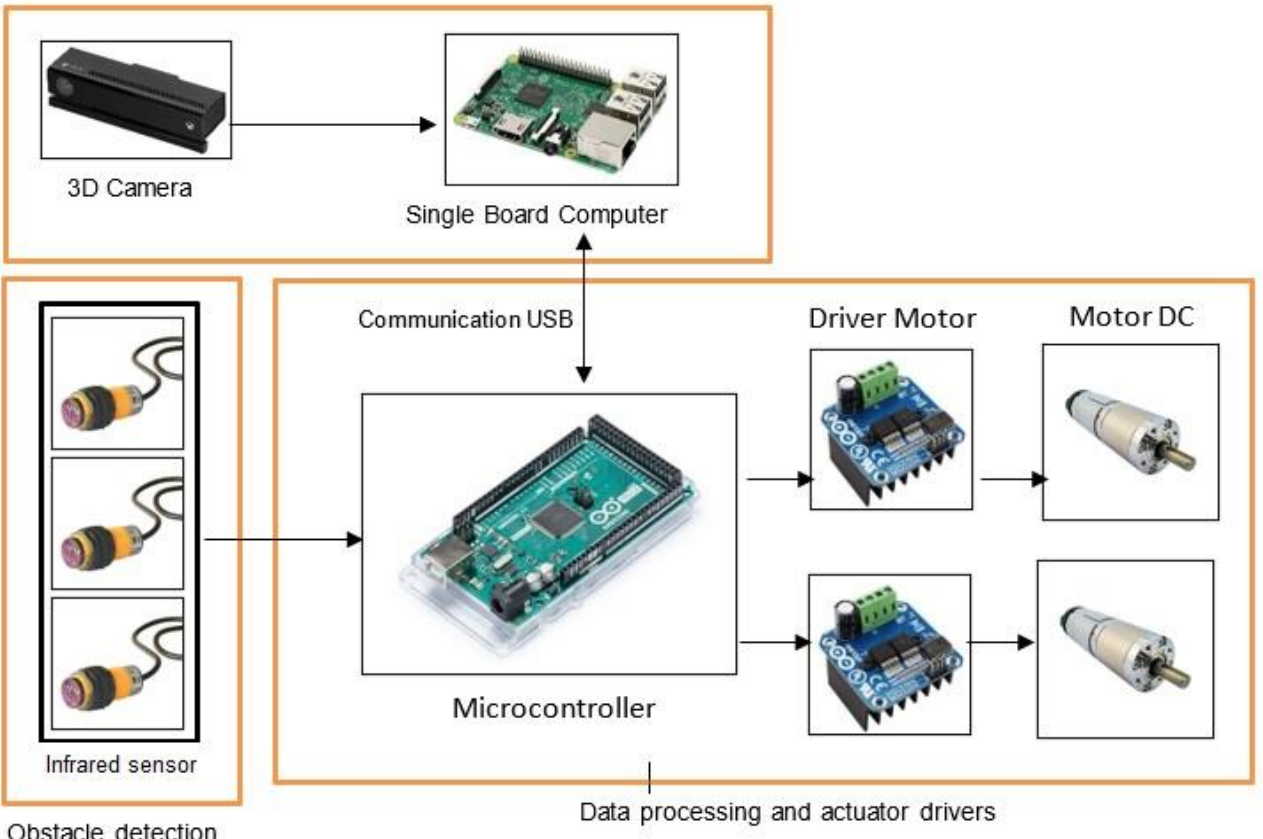

Fig. 2. Hardware Testing Design
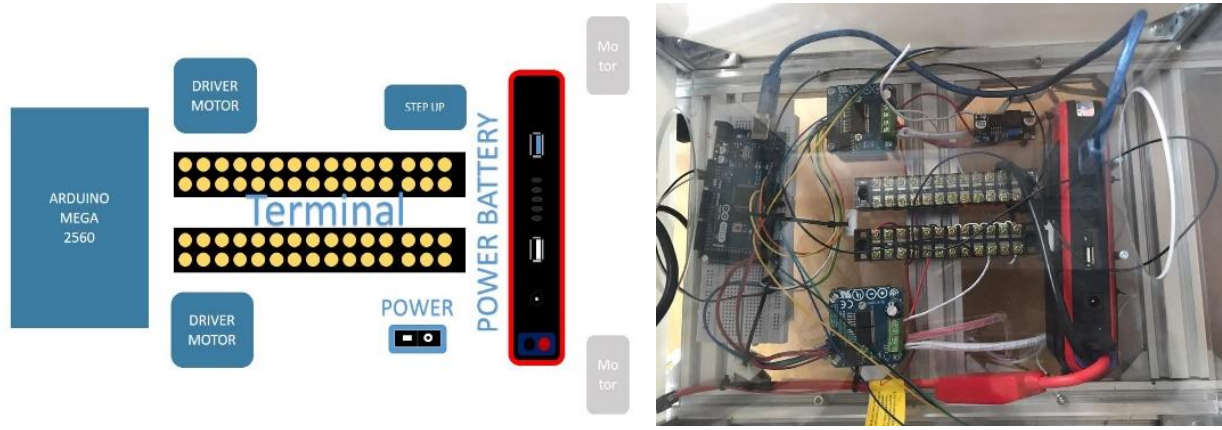

Fig. 3. Srobot Hardware Design

Based on the picture above, the device processes the image using an RGBD camera to obtain RGB data and the depth of the captured image. The data obtained will be sent to a single board computer, Raspberry Pi 3 , for processing on an embedded algorithm [8]. Processing results on a single board computer will be sent via USB serial communication connected to an Arduino microcontroller consisting of request data to drive a DC motor so that the transporter will be moved according to the planning and commands needed to find each object [9]. While the infrared sensor is used to prevent obstacles in front of the transporter so that the It will be moved if deemed to have obstacles. When robots are widely implemented in logistics, it is estimated that up to 40 percent of robotics can offer cost reductions [10]. 


\section{RESULTS AND DISCUSSION}

In this section, the results of research are explained and at the same time is given the comprehensive discussion. Results can be presented in figures, graphs, tables and others that make the reader understand easily. The discussion can be made in several sub-chapters. It is strongly suggested that comparison wih results from other published articles are provided to give more context and to strengthen the claim of novelty.

\subsection{Robot Operating System (ROS)}

ROS consists of meta-operating systems or frameworks that are open source in which there are operating systems in general, including hardware abstraction, lower-level device control, implementation of commonly used functions, and delivery of messages or data between processes and package management. In this research, ROS is used to program and control robots [11]. The block diagram of basic concepts of ROS is shown in Figure 4. This software provides tools that add new functionality to the robot, such as autonomous navigation and visual perception and there are many examples and source code, including sensors. The basic concept of the Robot Operating System consists of:

- Ros Master, provides the naming and registration of each networked node, tracking each publisher and subscriber to topics and services.

- Node, an executable program that does computing. It is the same as playing, where all topics and services are published by node.

- Messages, is an interface definition language (IDL) in the .msg file.

- Topic, used for communication between nodes. Each topic is given information that matches the type of message used.

- Service, is a communication tool, but is more flexible than topic.

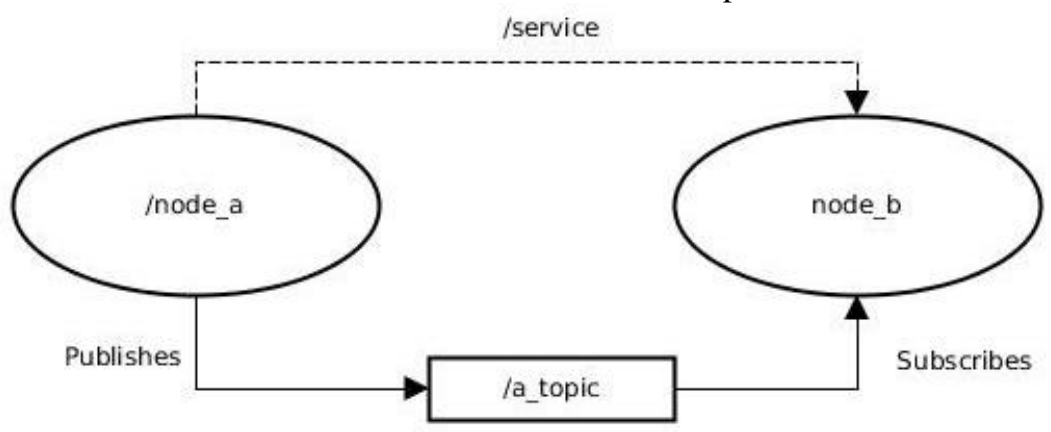

Fig. 4. Block Diagram of Basic Concepts of ROS

\subsection{Object Follower Algorithm}

Object follower algorithm method with HSV color detection is done by selecting pixel samples as a color reference to form the desired segment. Digital images use RGB color as the color reference standard, therefore the initial process in this method requires the conversion of the RGB to HSV color model [12]. To form a segment with the desired color, tolerance values are determined for each color dimension of HSV, then the tolerance values are used in the calculation of the adaptive threshold process. The results of the threshold process will form an area segment with a color according to the desired tolerance.

The color detection used in SROBOT is green. It is HSV: [50, 100, 100], [70, 255, 255]. When the camera sensor detects a color, the robot will automatically follow the color wherever the color moves.

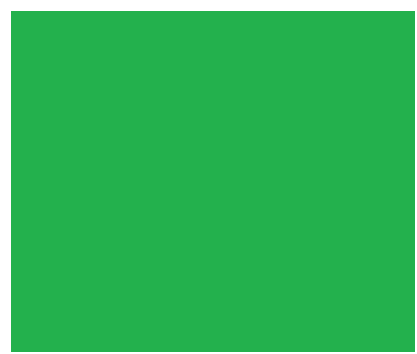

Fig. 5. The green color object 
Kinect 360 sensor (Figure 6) is a sensor component that uses serial communication that is connected to the Kinect USB sensor on a PC. It has a sensor voltage source which is a $12 \mathrm{~V}$ battery. Kinect XBOX 360 has a 1414 Kinect model that can be used for standalone Kinect adapters). The RGB camera owned by the 1414 model Kinect camera has a resolution of 640 x 480 pixels, so does an infrared camera having the same resolution, which is $640 \times 480$ pixels.

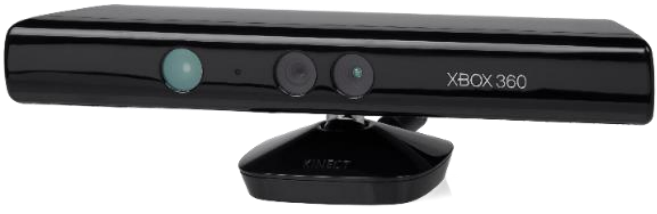

Fig. 6. Kinect 360

Testing is done by running the open Kinect library in IDE processing. This library contains calculations to activate it and can capture images displayed. The image is then displayed in real time in IDE processing using the Capture () class. Testing for Kinect cameras is divided into two, namely RGB camera testing and infrared camera testing. In this research, smart robot (Srobot) uses RGB camera testing to detect color objects.

\subsection{Aluminum Frame}

The parts that will be designed are the base of the transporter, the touchscreen display buffer section along with the camera, and the part that is used as a place to carry logistical goods (Figure 7, Figure 8, Figure 9). The initial prototype of Srobot is as follows. The robot mechanics above are the results of trial and error testing done by students with several experiments. as in other studies, this research is expected to be a platform that can support in an unstructured office environment and demonstrate avoidance protection [13]. After the robot mechanic is successful, then another test carried out is measuring the obstacle error tracking level.

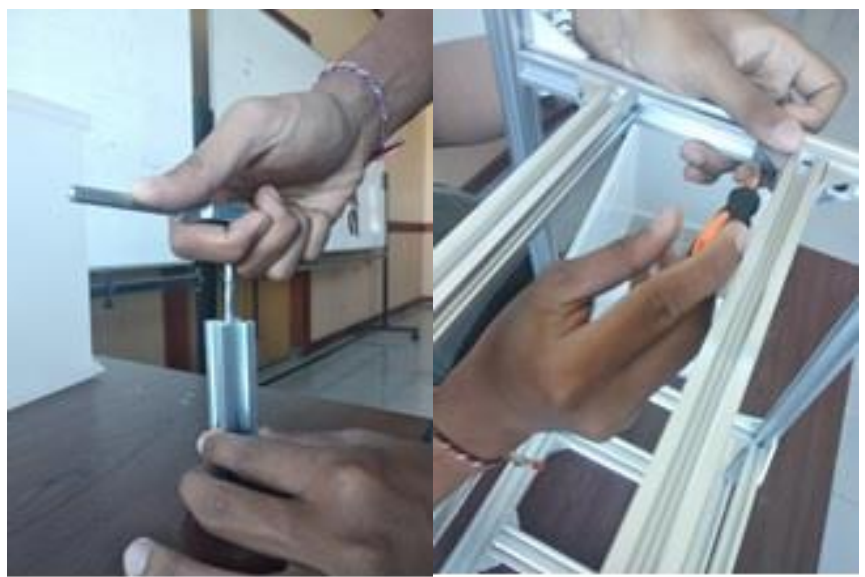

Fig. 7. Stage 1 robot mechanics
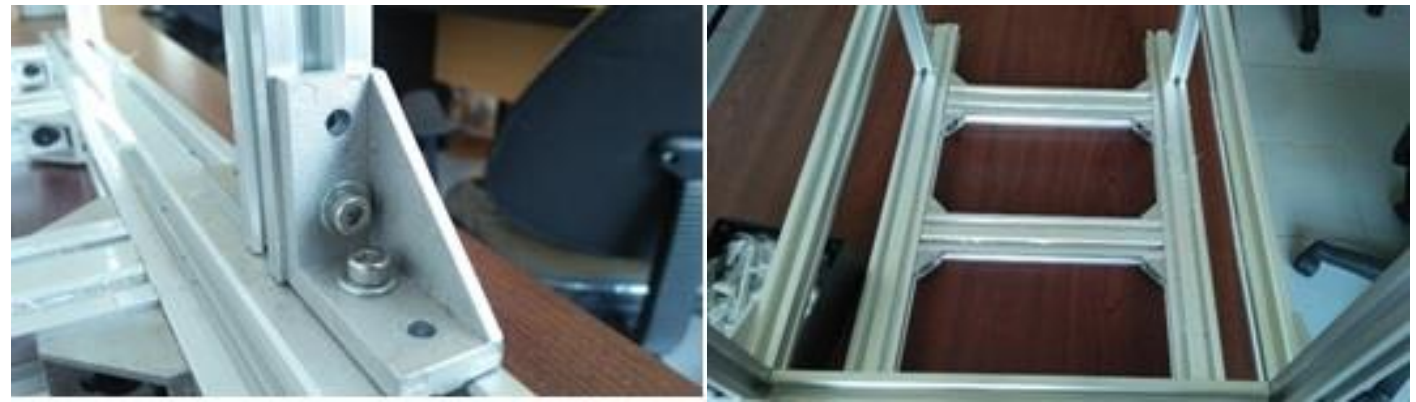

Fig. 8. Stage 2 robot mechanics 


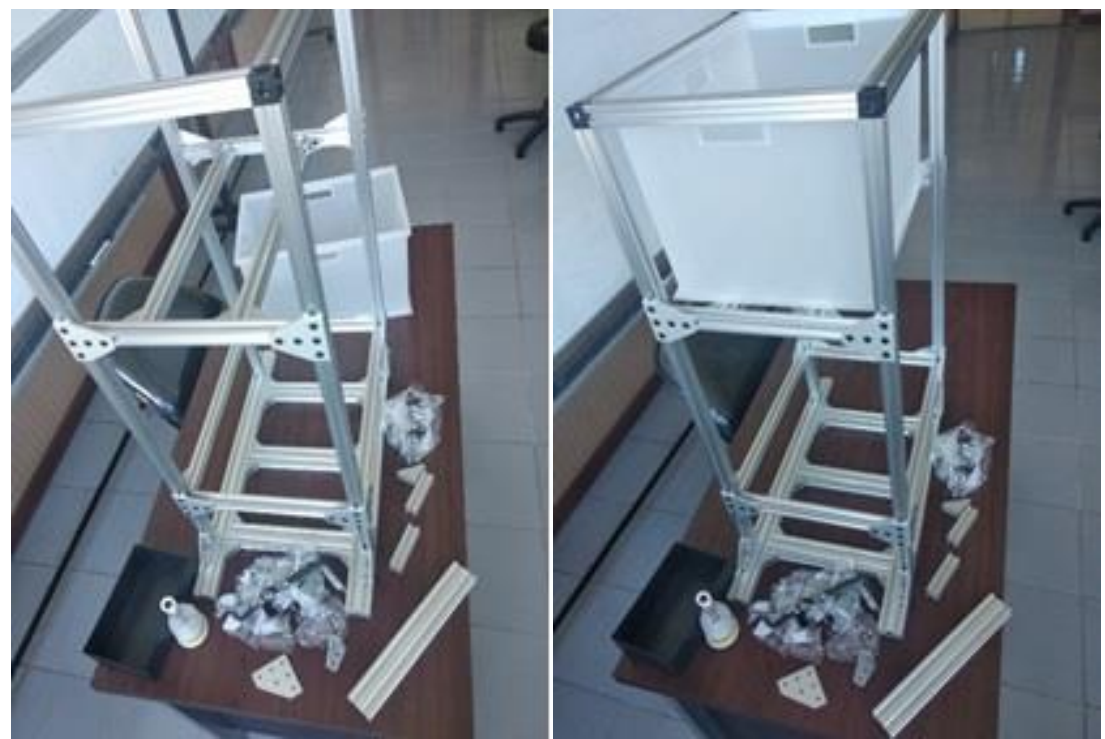

Fig. 9. Stage 3 robot mechanics

\subsection{Error Tracking Testing Results}

All logistics transporter platforms currently in use can navigate safely and avoid static and dynamic barriers. The ability to detect and track humans around robots has become a major focus [14]. In addition, the robot is expected to receive users by obtaining data depth to set and manage distances [15]. Adaptive algorithms can also be used in research, namely by utilizing sensor data testing via Kinect installed for tracking people and robots must retrieve data on each person who is walking [16][17]. So in this study we created intelligent logistic transporters by utilizing green detection before tracking human presence around. The depth of the data being tested is the error response on the right and left robot coordinate path, as in the following figure.

The Figure 10 is a graph of the error response tracking obstacle robot on the right. When a robot crosses a path with various obstacles, we also calculate what the error value is in the test. If the error value is zero, then the robot has reached the target object.

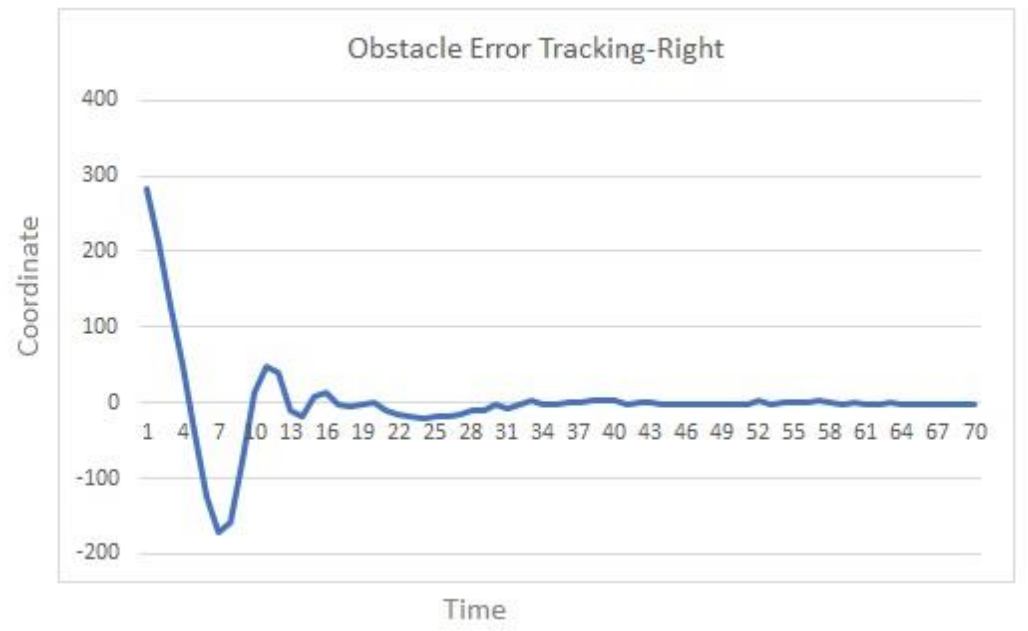

Fig. 10. Obstacle Error Tracking - Right

From Figure 10, it can be analyzed that at first the data received has a high error value, but then for trial and error we have got a small error value. The data is a test data repeatedly by making several possibilities when testing the robot path (Figure 11).

The graph of the left obstacle robot's tracking error response in Figure 12 and Figure 13 when the robot crosses the path with various obstacles, we also calculate what the error value is in testing. If the error value is zero, then the robot has reached the target object. 


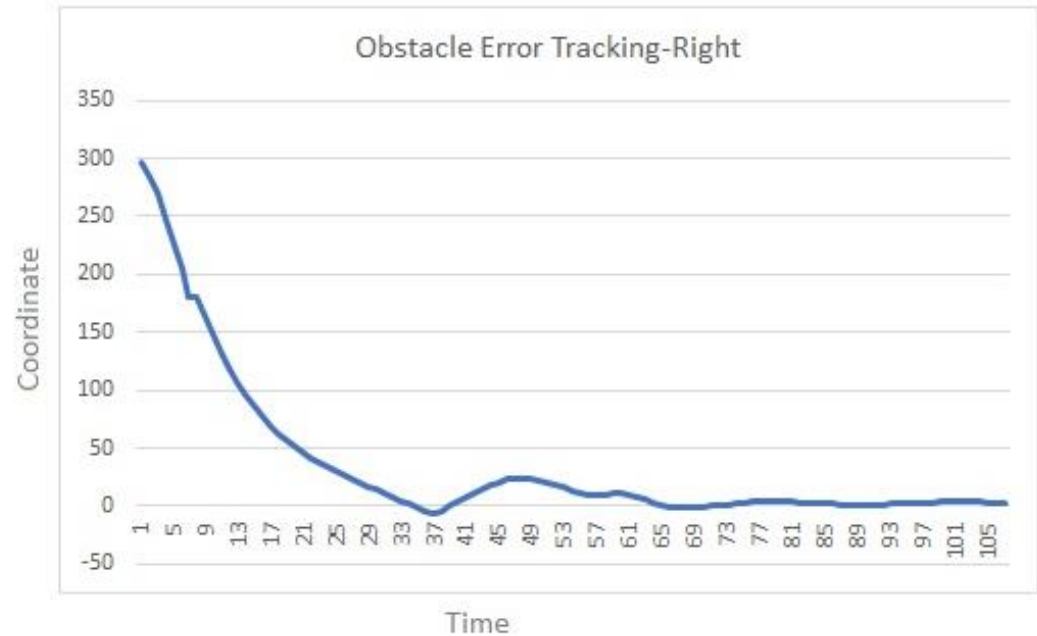

Fig. 11. Obstacle Error Tracking - Right

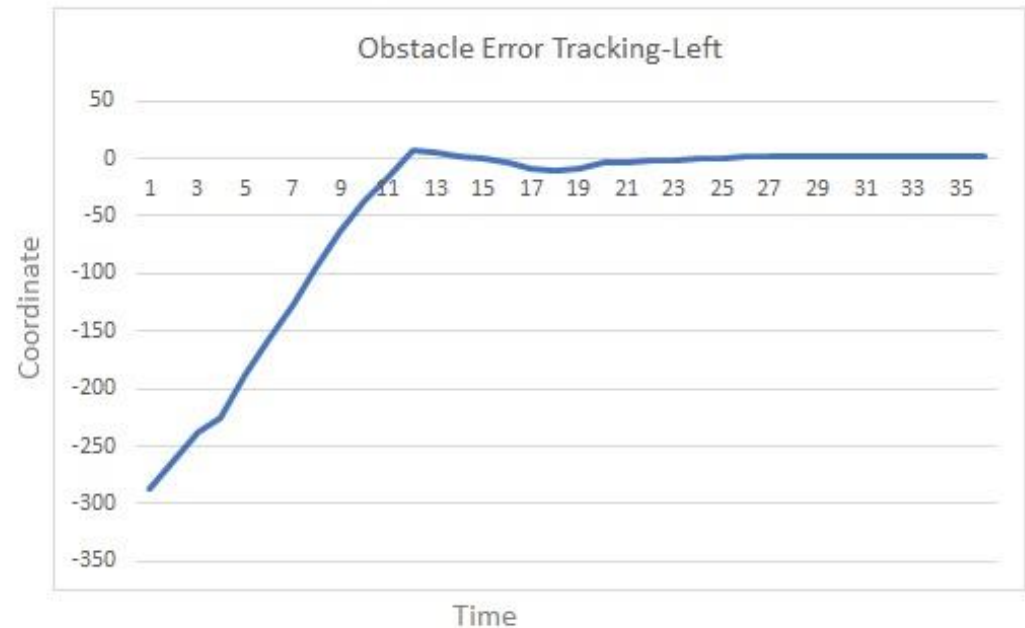

Fig. 12. Obstacle Error Tracking - Left

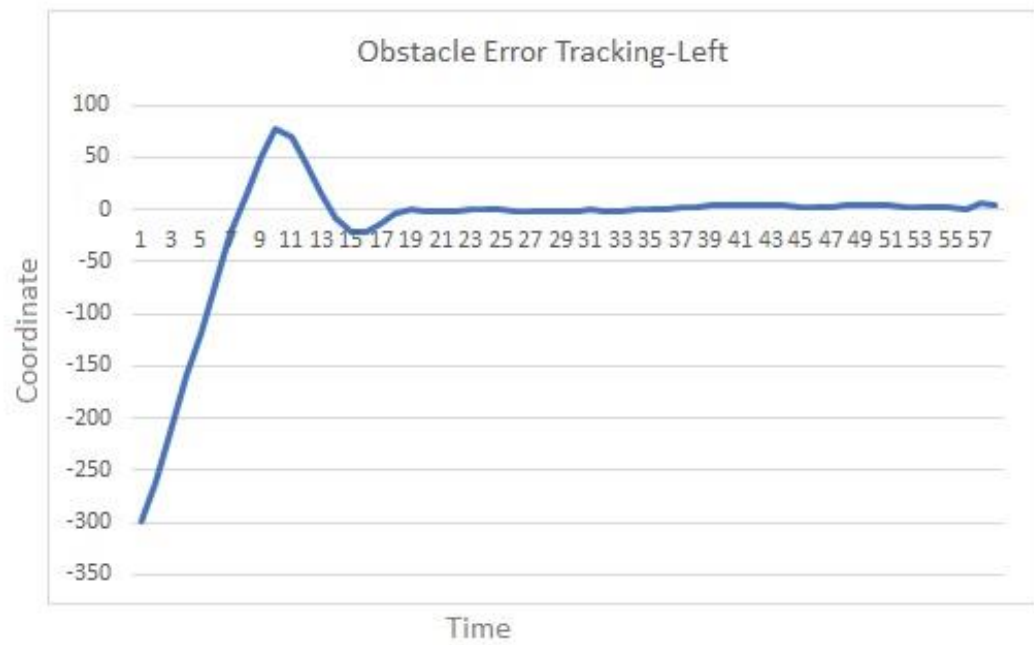

Fig. 13. Obstacle Error Tracking - Left

The prototype image of the intelligent robot that we made is in Figure 14, and the development for further research is to make the intelligent robot with two main algorithms, namely path planning and obstacle avoidance autonomously. 


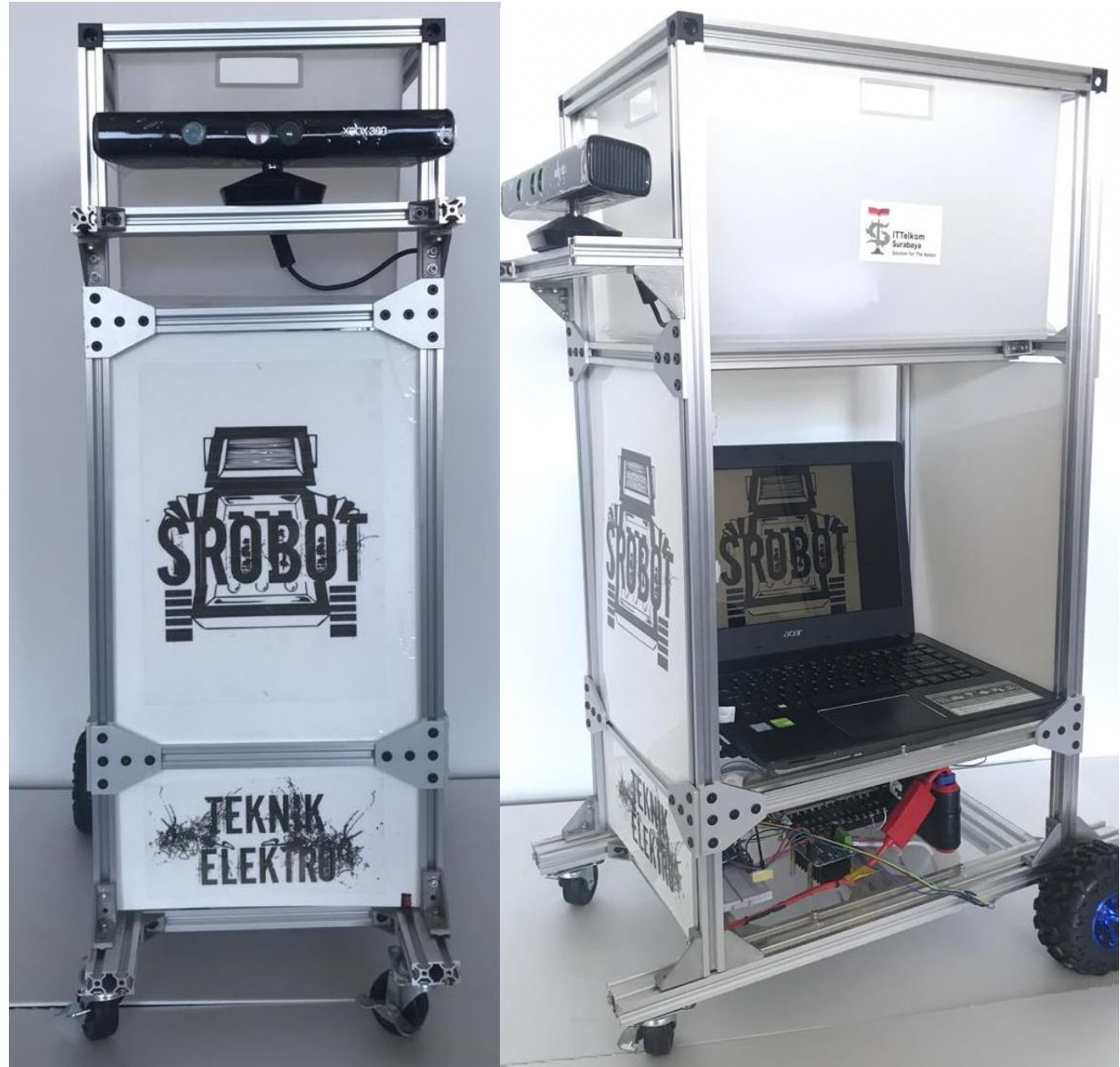

Fig. 14. Prototype of Smart Robot (Srobot)

\section{CONCLUSION}

Based on the research and discussion data described above, conclusions can be drawn from the system test results that can help move goods by following the movements of the object as long as the object is within the reach of the robot so that the robot recognizes the object by approaching to find the object. Object detection camera sensor respondents were declared feasible so that the use of object detection robot learning media can improve and be implemented at Institut Teknologi Telkom Surabaya.

\section{Acknowledgments}

This paper is a result of research conducted at Institut Teknologi Telkom Surabaya under 'Penelitian Dana I Program of the Lembaga Penelitian dan Pengabdian kepada Masyarakat'.

\section{REFERENCES}

[1] A. F. Pratiwi and S. D. Riyanto, "Sistem Penentuan Lokasi dan Penyimpanan Barang Menggunakan LabVIEW dan Sensor Ultrasonik," J. Teknol. dan Sist. Komput., vol. 5, no. 2, p. 75, 2017, doi: 10.14710/jtsiskom.5.2.2017.76-83.

[2] E. Castelló Ferrer, "The blockchain: A new framework for robotic swarm systems," Adv. Intell. Syst. Comput., vol. 881, pp. 1037-1058, 2019, doi: 10.1007/978-3-030-02683-7_77.

[3] Y. Liu, L. Wang, H. Huang, M. Liu, and C. Z. Xu, "A novel swarm robot simulation platform for warehousing logistics,” 2017 IEEE Int. Conf. Robot. Biomimetics, ROBIO 2017, vol. 2018-Janua, no. 61603376, pp. 2669-2674, 2018, doi: 10.1109/ROBIO.2017.8324822.

[4] M. Klumpp and C. Ruiner, "Regulation for Artificial Intelligence and Robotics in Transportation, Logistics and Supply Chain Management," Netw Ind Q, vol. 20, no. 2, pp. 3-7, 2018. Google Scholar

[5] D. Teso-Fz-Betoño, E. Zulueta, U. Fernandez-Gamiz, I. Aramendia, and I. Uriarte, "A Free Navigation of an AGV to a Non-Static Target with Obstacle Avoidance," Electronics, vol. 8, no. 2, p. 159, 2019, doi: 10.3390/electronics8020159. 
[6] M. Perdoch, D. M. Bradley, J. K. Chang, H. Herman, P. Rander, and A. Stentz, "Leader tracking for a walking logistics robot," IEEE Int. Conf. Intell. Robot. Syst., vol. 2015-Decem, pp. 2994-3001, 2015, doi: 10.1109/IROS.2015.7353790.

[7] "An Improved Indoor Robot Human-Following Navigation Model Using Depth Camera, Active IR Marker and Proximity Sensors Fusion," Robotics, vol. 7, no. 1, p. 4, 2018, doi: 10.3390/robotics7010004.

[8] DHL, "Blockchain in logistics," DHL Cust. Solut. Innov., pp. 1-28, 2018. Online

[9] Y. Nagumo and A. Ohya, "Human following behavior of an autonomous mobile robot using light-emitting device," Proceedings 10th IEEE International Workshop on Robot and Human Interactive Communication. ROMAN 2001 (Cat. No.01TH8591), Bordeaux, Paris, France, 2001, pp. 225-230, doi: 10.1109/ROMAN.2001.981906.

[10] T. Niemueller, G. Lakemeyer, S. Reuter, S. Jeschke, and A. Ferrein, "Benchmarking of Cyber-Physical Systems in Industrial Robotics: The Robocup Logistics League as a CPS Benchmark Blueprint," Cyber-Physical Syst. Found. Princ. Appl., pp. 193-207, 2016, doi: 10.1016/B978-0-12-803801-7.00013-4.

[11] D. Sun, A. Kleiner, and C. Schindelhauer, "Decentralized Hash Tables for Mobile Robot Teams Solving IntraLogistics Tasks," Aamas-10, no. Aamas, pp. 923-930, 2010. Online

[12] M. Irfan, "Desain Dan Implementasi Kendali Kecepatan Motor Pada Robot Dengan Empat Roda Omni Menggunakan Metode Logika Fuzzy Design and Implementation of Motor Speed Control on Four Omni Wheeled Robot Using Fuzzy Logic Method," e-Proceeding of Engineering, vol. 3, no. 2, pp. 1344-1351, 2016. Online

[13] C. N. Viet and I. Marshall, "Vision-Based Obstacle Avoidance for a Small, Low-Cost Robot," pp. 275-279, 2015, doi: 10.5220/0001648302750279.

[14] C. Dondrup, N. Bellotto, F. Jovan, and M. Hanheide, "Real-time multisensor people tracking for human-robot spatial interaction," Work. Mach. Learn. Soc. Robot. Int. Conf. Robot. Autom., 2015. Online

[15] G. Cu, A. G. Ang, A. R. Ballesteros, and J. C. Rentoy, "Human following robot using kinect sensor," La Salle Univ. Res. Congr., pp. 1-7, 2013. Online

[16] G. Doisy, A. Jevtić, E. Lucet, and Y. Edan, "Adaptive person-following algorithm based on depth images and mapping," IROS 2012 Work. Robot Motion Plan., pp. 43-48, 2012. Online

[17] T. Niemueller, G. Lakemeyer, and A. Ferrein, "The RoboCup Logistics League as a Benchmark for Planning in Robotics," Proc. ICAPS Work. Plan. Robot., p. 6, 2015. Online

\section{BIOGRAPHY OF AUTHORS}

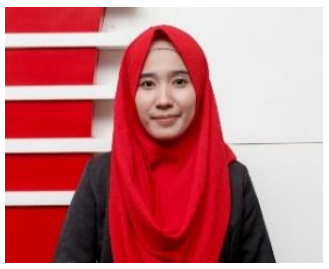

Lora Khaula Amifia

loraamifia@ittelkom-sby.ac.id

Control Engineering, Non-linear Systems, Artificial Intelligence

Electrical Engineering, Institut Teknologi Telkom Surabaya, Surabaya, Indonesia

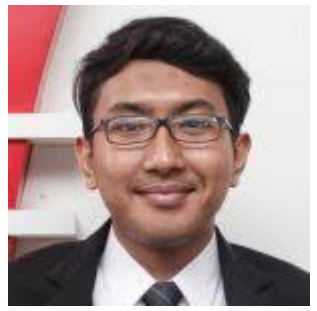

\section{Moch. Iskandar Riansyah}

iskandar@ittelkom-sby.ac.id

Robotics, Control, Artifcial Intellegence, Computer Vision

Electrical Engineering, Institut Teknologi Telkom Surabaya, Surabaya, Indonesia

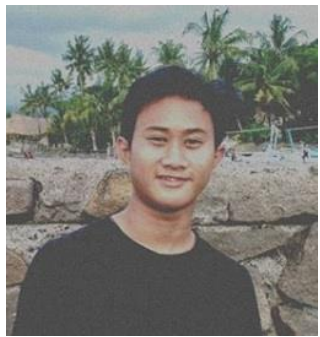

\section{Putu Duta Hasta Putra}

dutahasta@ittelkom-sby.ac.id

Electrical Engineering, Institut Teknologi Telkom Surabaya, Surabaya, Indonesia 
This Page is left Blank 